\title{
Impact of Zero Order Unconverted Light on Beam Pointing
}

Dan Kalantar, Sham Dixit, and Richard Lyons

August 24, 1999

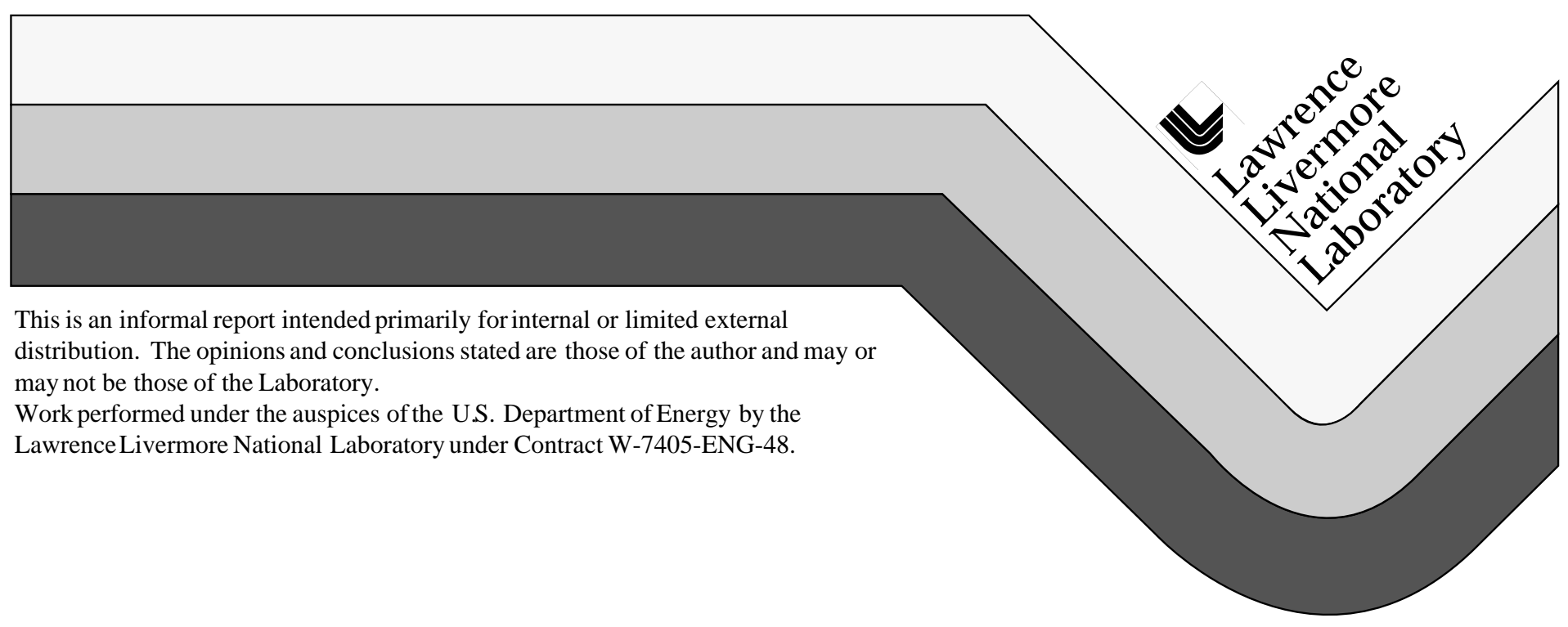




\section{DISCLAIMER}

This document was prepared as an account of work sponsored by an agency of the United States Government. Neither the United States Government nor the University of California nor any of their employees, makes any warranty, express or implied, or assumes any legal liability or responsibility for the accuracy, completeness, or usefulness of any information, apparatus, product, or process disclosed, or represents that its use would not infringe privately owned rights. Reference herein to any specific commercial product, process or service by trade name, trademark, manufacturer, or otherwise, does not necessarily constitute or imply its endorsement, recommendation, or favoring by the United States Government or the University of California. The views and opinions of authors expressed herein do not necessarily state or reflect those of the United States Government or the University of California, and shall not be used for advertising or product endorsement purposes.

This report has been reproduced Directly from the best available copy.

Available to DOE and DOE contractors from the Office of Scientific and Technical Information

P.O. Box 62, Oak Ridge, TN 37831

Prices available from (615) 576-8401, FTS 626-8401

Available to the public from the National Technical Information Service

U.S. Department of Commerce 5285 Port Royal Rd., Springfield, VA 22161 
National Ignition Facility Project

Mail Station L-473

Ext: 2-6147

August 24, 1999

NIF-0033352

To: Distribution

From: Dan Kalantar, Sham Dixit, and Richard Lyons

Subject: Impact of zero order uncoverted light on beam pointing

There is a significant amount of unconverted light incident in the NIF target chamber. The baseline plan for managing this light is to use a sub-aperture CSG design. This CSG selection impacts the target chamber and nearopposing FOAs due to: (1) zero order unconverted light footprint, and (2) high order dispersed unconverted light. In this memo we describe the impact of the zero order light on the range of beam pointing for individual beams. We show that zero order footprint for $1 w$ light enters into the near-opposite FOAs for several ports if the beams are pointed away from the target chamber center. Additionally, for the case where $3 w$ is allowed to propagate past target chamber center, the converted light may enter into the near-opposite FOAs. The second aperture in the PAM is required to protect the FOAs and still accommodate offset beam pointing on NIF. We present details on the aperture requirements to accommodate a range of beam pointing.

\section{Background}

The NIF target chamber is designed with no directly opposing ports. This is accomplished using a rotational offset of $11.25^{\circ}$ for the beam port pattern on the top vs. the bottom of the chamber. In this configuration, the footprint of unconverted light on the opposite wall of the chamber is located between two adjacent nearly opposing beams. As beams are pointed away from chamber center, however, the footprint of the unconverted light may be directed into the aperture for a nearly opposing beam.

For the Haan pulse shape, the average fluence of the zero-order unconverted light (light that is not deflected with the sub-aperture color separation grating) is approximately $13 \mathrm{~J} / \mathrm{cm}^{2}$ on the opposite wall of the NIF target chamber. If this is allowed to propagate into the FOA, the average fluence is approximately $6 \mathrm{~J} / \mathrm{cm}^{2}$ at the debris shield, with peak fluence up to an order of magnitude higher.

The average fluence due to unconverted light exceeds the damage threshold for the first wall material and for all aluminum structures in the 
FOA. To prevent ablation of the first wall by the high intensity unconverted light from impacting the final optics of the a near-opposing FOA, we need to confine the footprint of the zero-order light to fall on the first wall, and not into a near-opposite FOA. If this cannot be avoided, then a mitigation strategy for absorbing this light is required.

In addition, for the case where targets such as gasbags or point backlighter fibers, there is the possibility that some of the converted $3 \mathrm{w}$ light will propagate to the opposite wall, impacting the near-opposite FOAs. This may be at an average fluence as high as $8 \mathrm{~J} / \mathrm{cm}^{2}$ at the debris shield of a nearopposite FOA. Again, the peak fluence may be higher due to modulation in the beam.

\section{Options to protect the FOA}

There are several options to protect the nearly opposing FOAs:

\section{Do nothing.}

The fluence of $x$-rays at the debris shield may be as high as $1 \mathrm{~J} / \mathrm{cm}^{2}$. Shielding provided to protect the $\mathrm{Al}$ surfaces from the $\mathrm{x}$-rays may also protect from converted and unconverted light. However, while the $x$-ray fluence will be nearly uniform at the FOA, the fluence of unconverted light will have an average of up to $6 \mathrm{~J} / \mathrm{cm}^{2}$ and a peak value as much as an order of magnitude higher. This may result in substantially more debris generated near the debris shield. We recommend that the light be managed so that high intensity unconverted $1 \mathrm{w}$ or converted $3 \mathrm{w}$ does not enter near-opposite FOAs.

\section{Impose limits on the range of pointing on some of the beams}

For maximum experimental design flexibility, it is desirable not to impose limits on the range of beam pointing. Engineering and other practical constraints may impose separate limits on beam pointing, but we do not consider this option here.

\section{Block the zero order unconverted light with large shields at target chamber center for all target shots}

The shields required to block all the zero order unconverted light at the target plane would be approximately $50 \mathrm{~mm}$ diameter. Such shields would be the source of significant debris and shrapnel in the target chamber. In addition, this would not be effective for targets with backlighter foils, or for beams that are pointed at a backlighter, typically the situation for a beam that is incident in a near-opposite FOA. We do not consider this option here.

\section{Reduce the aperture for beams that impact near-opposite FOAs using a telescope adjustment.}

There is a telescope adjustment in each beam located in the PAM (ECR228). This is intended to allow small magnification changes from 0.95- 
1.02. In order to use this to protect near-opposite FOAs for full beam pointing about target chamber center, the telescope adjustment would have to cover a range from less than 0.5 to 1.0 magnification. To extend the range to a magnification of 0.5 is unreasonable since it may put the beamlines at risk of damage if a telescope is left in the wrong position for a high energy shot. We do not consider this option here.

\section{Clip one edge of the beam in the PAM, or just turn off a single beam.}

This option would offer the most flexibility in target design without impacting the target chamber itself. In this memo we discuss the requirements for clipping beams based on the unconverted light incident at the target chamber wall. The effect of $3 w$ is also discussed.

\section{Analysis of impact}

The IDL model of unconverted light (ULMV, Research Sciences, Inc.) was used to evaluate the interference of the high intensity laser light on nearopposite FOAs. This was then checked with a Pro/E model. We measured the proximity of the beam footprint ( $1 \mathrm{w}$ zero order unconverted light and converted $3 \mathrm{w}$ light) to the aperture in the first wall for the near-opposite FOAs, and then we evaluated the limit on beam pointing away from chamber center if no aperture is introduced.

We determined the overlap for beams pointed away from the target chamber center to estimate the maximum interference that can be expected. A $\pm 30 \mathrm{~mm}$ pointing offset in the two transverse directions (relative to the beam) was used with the maximum beam defocus of $-48 \mathrm{~mm}$. These estimates were also repeated for a $50 \mathrm{~mm}$ transverse range of pointing. Note that the NIF beams are nearly $\mathrm{f} / 20$. The defocus does not affect the overlap significantly.

We used an FOA aperture size of $640 \times 685 \mathrm{~mm}$ located at $4632 \mathrm{~mm}$ from the target chamber center to estimate the beam-FOA interference. This FOA aperture is defined by a flashing aperture frame that is $630 \times 675 \mathrm{~mm}$ with a $\pm 5 \mathrm{~mm}$ placement tolerance as described in design document NIF5002563.

Figure 1 shows an equatorial projection of the top half of the NIF target chamber. The footprint of quads of beams entering through the FOA beam ports on the top half of the chamber are shown inside the outlines of the FOA ports and beam apertures in the first wall. In addition, the footprint of each beam entering through ports in the bottom of the chamber are shown incident on the first wall between the beam ports in the top half of the chamber. Marked on this figure are the locations where the zero order unconverted light footprint impacts a near-opposite FOA when the beam is pointed up to $50 \mathrm{~mm}$ offset from chamber center. Beams from a total of 32 quads are affected.

We calculated the closest distance between the nearest beam footprints and the first wall opening for an adjacent beam for each pair of beam quad 
ports on NIF. The results are shown in Table 1. The range of motion for a full aperture beam before it interferes with the near-opposite FOA aperture is also listed in this table. For a $30 \mathrm{~mm}$ transverse offset in the $\pm x$-direction (See Fig. 3), the footprint of that beam moves by $\pm(4632 \mathrm{~mm}+7700 \mathrm{~mm}) /(7700$ $\mathrm{mm})= \pm 48 \mathrm{~mm}$ at the first wall. In order to achieve a $\pm 50 \mathrm{~mm}$ range of pointing, the footprint of the beam moves by $\pm 83 \mathrm{~mm}$ at the first wall. Note that we have included only those beams that interfere when the beam is pointed up to $50 \mathrm{~mm}$ from target chamber center in any direction.

Figure 2a shows an enlarged view of the beam footprints from Q43B (port 59) incident near port 15. In this case, the footprint of the $1 \mathrm{w}$ is about 5 $\mathrm{mm}$ from the FOA aperture for the Q25T beams. As the Q43B beams are pointed off chamber center by up to $50 \mathrm{~mm}$, the unconverted light footprint will enter the FOA aperture at port 15 if the corner of the beam is not clipped. The corresponding $3 \mathrm{w}$ footprint is shown in Figure $2 \mathrm{~b}$. Because of the larger footprint, we see that if the $3 \mathrm{w}$ beam is pointed to chamber center and allowed to propagate past the target, it enters into the near-opposing FOA. Due to the symmetry of beam port locations on NIF, there are eight such ports with this interference in the upper half and eight in the lower half of the target chamber.

The close proximity of the beam footprints and beam pointing limitations before interference occurs as shown in Table 1, indicate that we need to reduce the beam size to allow the full range of pointing. This results in a loss of available energy for that quad. We calculate the loss in beam area (and energy) for the 4 beams in each affected quad. This is expressed as an equivalent number of beamlets out of 4 for the 2 cases of a) $30 \mathrm{~mm}$ pointing offset and b) $50 \mathrm{~mm}$ pointing offset. These are shown in Table 2. Note that in some cases to achieve the full range of pointing for all four beams within a quad, the area lost by placing an aperture in the PAM is more than the single beam area. In this situation, it makes more sense to just turn off one beam in the quad.

We have assessed the requirements for beam apertures based on beam pointing for each quad of beams, and the results are presented as a beam alignment recipe in Table 3. For example, beams in quad Q11T enter through port 17 may impact the FOA located on port 54. Specifically, if the Q11T beams are aligned in the $-x$ direction, by $\leq 30 \mathrm{~mm}$, we recommend an aperture be used to reduce the beam area. And, if the beam is aligned beyond $30 \mathrm{~mm}$, we recommend removing the aperture and turning off beam Q1 in this quad (See Fig. 3).

A total of 40 quads must have an aperture in the PAM. Detailed aperture shapes and sizes will need to be calculated and must include any corrections for limits on beam pointing for specific beams that may arise, for example due to the mirror structures in the switch yards and target area. The approximate shape of each aperture is shown in the listing of notes following Table 3. Note that these apertures are drawn to represent the shape of the beam as it enters the FOA. The orientation of the aperture in the PAM will be 
rotated by $90^{\circ}$. The direction of this rotation depends on whether the quad has a LM6 mirror.

The approximate apertures have been defined for the Indirect Drive NIF configuration. When we consider other target configurations that use the direct drive ports (direct drive or tetrahedral targets) or NWET applications, the aperture sizes and the requirements on beam pointing may be different. 
Table 1: Listing of beams affected by the zero-order light incident close to the near-opposite FOA. The range of pointing at target chamber center without impact is shown based on the $1 \mathrm{w}$ and $3 \mathrm{w}$ beam footprints. The limit based on $1 \mathrm{w}$ applies for all cases. The limit based on $3 \mathrm{w}$ applies for cases where the $3 \mathrm{w}$ beam may propagate past target chamber center (such as for a gas bag or a point projection fiber backlighter).

\begin{tabular}{|c|c|c|c|c|c|}
\hline $\begin{array}{l}\text { Beam cone } \\
\text { interaction }\end{array}$ & $\begin{array}{c}\text { Affected } \\
\text { quads } \\
\text { (beam port } \\
\text { numbers) }\end{array}$ & $\begin{array}{c}\text { Nearest } \\
\text { approach } \\
\text { of 1w (at } \\
\text { wall) }\end{array}$ & $\begin{array}{c}\text { Max offset } \\
\text { pointing at } \\
\text { TCC in } \\
\text { azimuth - } \\
\text { limit based } \\
\text { on } 1 w \text { at } \\
\text { wall }\end{array}$ & $\begin{array}{c}\text { Nearest } \\
\text { approach } \\
\text { of } 3 w \text { (at } \\
\text { wall) }\end{array}$ & $\begin{array}{c}\text { Max offset } \\
\text { pointing at } \\
\text { TCC in } \\
\text { azimuth - } \\
\text { limit based } \\
\text { on } 3 w \text { at } \\
\text { wall }\end{array}$ \\
\hline $23.5^{\circ}-23.5^{\circ}$ & $\begin{array}{l}1-72 \\
2-69 \\
3-70 \\
4-71\end{array}$ & $42 \mathrm{~mm}$ & $26 \mathrm{~mm}$ & $20 \mathrm{~mm}$ & $12 \mathrm{~mm}$ \\
\hline $44.5^{\circ}-44.5^{\circ}$ & $\begin{array}{c}9-61 \\
10-62 \\
11-63 \\
12-64 \\
13-57 \\
14-58 \\
15-59 \\
16-60 \\
\end{array}$ & $15 \mathrm{~mm}$ & $9 \mathrm{~mm}$ & $\begin{array}{c}-5 \mathrm{~mm} \\
\text { *overlaps* }^{*}\end{array}$ & $\bar{n} / \mathbf{a}$ \\
\hline $44.5^{\circ}-50^{\circ}$ & $\begin{array}{c}9-53 \\
18-62 \\
11-55 \\
20-64 \\
13-49 \\
22-58 \\
15-51 \\
24-60\end{array}$ & $39 \mathrm{~mm}$ & $24 \mathrm{~mm}$ & $20 \mathrm{~mm}$ & $12 \mathrm{~mm}$ \\
\hline $50^{\circ}-50^{\circ}$ & $\begin{array}{l}17-54 \\
19-56 \\
21-50 \\
23-52 \\
22-51 \\
24-53 \\
18-55 \\
20-49\end{array}$ & $80 \mathrm{~mm}$ & $\begin{array}{l}38 \mathrm{~mm} \\
50 \mathrm{~mm}\end{array}$ & $\begin{array}{l}41 \mathrm{~mm} \\
60 \mathrm{~mm}\end{array}$ & $37 \mathrm{~mm}$ \\
\hline
\end{tabular}


Table 2: Equivalent beamlets lost per quad due to aperture requirements based on $30 \mathrm{~mm}$ and $50 \mathrm{~mm}$ range of pointing. These are shown based on propagating the focussed $3 \mathrm{w}$ beam past chamber center since that is the more restrictive case.

\begin{tabular}{|c|c|c|c|c|}
\hline $\begin{array}{l}\text { Beam cone } \\
\text { interaction }\end{array}$ & $\begin{array}{l}\text { Affected } \\
\text { quads } \\
\text { (beam port } \\
\text { numbers) }\end{array}$ & $\begin{array}{c}\text { Equivalent } \\
\text { beamlets lost* } \\
\text { due to } \\
\text { aperture in } \\
\text { PAM for } 30 \\
\text { mm pointing } \\
(3 w) \text { (Approx) }\end{array}$ & $\begin{array}{c}\text { Equivalent } \\
\text { beamlets lost } \\
\text { due to } \\
\text { aperture in } \\
\text { PAM for } 50 \\
\text { mm pointing } \\
\text { (3w) (Approx) }\end{array}$ & $\begin{array}{c}\text { Proposed } \\
\text { solution for } \\
\text { offset pointing }\end{array}$ \\
\hline $23.5^{\circ}-23.5^{\circ}$ & $\begin{array}{l}1-72 \\
2-69 \\
3-70 \\
4-71\end{array}$ & 0.36 & 1.00 & $\begin{array}{l}\text { - Aperture to } \\
\text { allow } 30 \mathrm{~mm} \text {. } \\
\text { - Turn beam off } \\
\text { for } 50 \mathrm{~mm}\end{array}$ \\
\hline $44.5^{\circ}-44.5^{\circ}$ & $\begin{array}{c}9-61 \\
10-62 \\
11-63 \\
12-64 \\
13-57 \\
14-58 \\
15-59 \\
16-60 \\
\end{array}$ & 0.96 & 1.60 & $\begin{array}{l}\text { - Aperture for } \\
\text { pointing at TCC } \\
\text { when beam } \\
\text { propagates past } \\
\text { TCC } \\
\text { - Turn off } 1 \\
\text { beam for offset } \\
\text { pointing }\end{array}$ \\
\hline $44.5^{\circ}-50^{\circ}$ & $\begin{array}{c}9-53 \\
18-62 \\
11-55 \\
20-64 \\
13-49 \\
22-58 \\
15-51 \\
24-60\end{array}$ & 0.4 & 1.08 & $\begin{array}{l}\text { - Aperture to } \\
\text { allow } 30 \mathrm{~mm} \\
\text { - Turn } 1 \text { beam } \\
\text { off for up to } 50 \\
\mathrm{~mm}\end{array}$ \\
\hline $50^{\circ}-50^{\circ}$ & $\begin{array}{l}17-54 \\
19-56 \\
21-50 \\
23-52 \\
22-51 \\
24-53 \\
18-55 \\
20-49\end{array}$ & 0.32 & 0.84 & $\begin{array}{l}\text { - Aperture to } \\
\text { allow } 30 \mathrm{~mm} \\
\text { - Turn off } 1 \\
\text { beam for up to } \\
50 \mathrm{~mm} \\
\text { - Aperture to } \\
\text { allow } 30 \mathrm{~mm}^{* *} \\
\text { - Turn off } 1 \\
\text { beam for up to } \\
50 \mathrm{~mm}\end{array}$ \\
\hline
\end{tabular}

* This is out of 4 beams total since the aperture located before the 1:4 split. When this exceeds 1.0, it makes more sense to just turn off the single beam causing the interference.

** Fractional beam area lost due to $50 \mathrm{~mm}$ pointing is small, but this is in addition to loss from pointing in opposite direction and the impact on other beam quads. We propose defining the aperture to allow only $30 \mathrm{~mm}$ range of pointing to limit the loss introduced with a dual purpose aperture. 
Table 3: Summary of alignment range limits and required aperture for backlighter pointing. This table includes the impact of some beams on 2 different near-opposite FOA ports.

\begin{tabular}{|c|c|c|c|c|}
\hline $\begin{array}{l}\text { Affected } \\
\text { Quad }\end{array}$ & $\begin{array}{l}\text { FOA Port } \\
\text { No. }\end{array}$ & $\begin{array}{c}\text { Near- } \\
\text { opposing } \\
\text { FOA ports } \\
\text { impacted }\end{array}$ & \begin{tabular}{|c|} 
Azimuthal \\
direction (x) \\
for beam \\
pointing \\
that affects \\
the near \\
opposite \\
port listed
\end{tabular} & $\begin{array}{l}\text { How to accommodate } \\
\text { beam pointing }\end{array}$ \\
\hline Q11T & 17 & 54 & - & See note 1 \\
\hline Q12T & 10 & 62 & - & See note 3 \\
\hline Q13T & 5 & & & No impact \\
\hline Q14T & 9 & 61,53 &,-+ & See note 5 \\
\hline Q15T & 1 & 72 & - & See note 1 \\
\hline Q16T & 18 & 55,62 &,-+ & See note 7 \\
\hline Q21T & 24 & 53,60 &,-+ & See note 7 \\
\hline Q22T & 16 & 60,52 &,-++ & See note 3 \\
\hline Q23T & 23 & 52 & - & See note 1 \\
\hline Q24T & 4 & 71 & - & See note 1 \\
\hline Q25T & 15 & 59,51 &,-+ & See note 5 \\
\hline Q26T & 8 & & & No impact \\
\hline Q31T & 22 & 51,58 &,-++ & See note 7 \\
\hline Q32T & 14 & 58 & - & See note 3 \\
\hline $\bar{Q}$ Q33 & 3 & 70 & - & See note 1 \\
\hline Q34T & 21 & 50 & - & See note 1 \\
\hline Q35T & 13 & 57,49 &,-+ & See note 5 \\
\hline Q36T & 7 & & & No impact \\
\hline Q41T & 6 & & & No impact \\
\hline Q42T & 2 & 69 & - & See note 1 \\
\hline Q43T & 11 & 63,55 &,-+ & See note 5 \\
\hline Q44T & 20 & 49,64 &,-+ & See note 7 \\
\hline Q45T & 12 & 64 & - & See note 3 \\
\hline Q46T & 19 & 56 & - & See note 1 \\
\hline
\end{tabular}




\begin{tabular}{|c|c|c|c|c|}
\hline $\begin{array}{l}\text { Affected } \\
\text { Quad }\end{array}$ & $\begin{array}{l}\text { FOA Port } \\
\text { No. }\end{array}$ & $\begin{array}{c}\text { Near- } \\
\text { opposing } \\
\text { FOA ports } \\
\text { impacted }\end{array}$ & \begin{tabular}{|c|} 
Azimuthal \\
direction (x) \\
for beam \\
pointing \\
that affects \\
the near \\
opposite \\
port listed
\end{tabular} & $\begin{array}{l}\text { How to accommodate } \\
\text { beam pointing }\end{array}$ \\
\hline Q11B & 50 & 21 & + & See note 2 \\
\hline Q12B & 58 & 22,14 &,-++ & See note 6 \\
\hline Q13B & 49 & 13,20 &,-++ & See note 8 \\
\hline Q14B & 57 & 13 & + & See note 4 \\
\hline Q15B & 69 & 2 & + & See note 2 \\
\hline Q16B & 65 & & & No impact \\
\hline Q21B & 68 & & & No impact \\
\hline Q22B & 64 & 20,12 &,-+ & See note 6 \\
\hline Q23B & 56 & 19 & + & See note 2 \\
\hline Q24B & 72 & 1 & + & See note 2 \\
\hline Q25B & 63 & 11 & + & See note 4 \\
\hline Q26B & 55 & 11,18 &,-+ & See note 8 \\
\hline Q31B & 67 & & & No impact \\
\hline Q32B & 62 & 18,10 &,-++ & See note 6 \\
\hline Q33B & 71 & 4 & + & See note 2 \\
\hline Q34B & 54 & 17 & + & See note 2 \\
\hline Q35B & 61 & 9 & + & See note 4 \\
\hline Q36B & 53 & 9,24 &,-+ & See note 8 \\
\hline Q41B & 51 & 15,22 &,-+ & See note 8 \\
\hline Q42B & 70 & 3 & + & See note 2 \\
\hline Q43B & 59 & 15 & + & See note 4 \\
\hline Q44B & 66 & & & No impact \\
\hline Q45B & 60 & 24,16 &,-+ & See note 6 \\
\hline Q46B & 52 & 23 & + & See note 2 \\
\hline
\end{tabular}


Table 3 (cont'd): Notes for offset beam pointing:

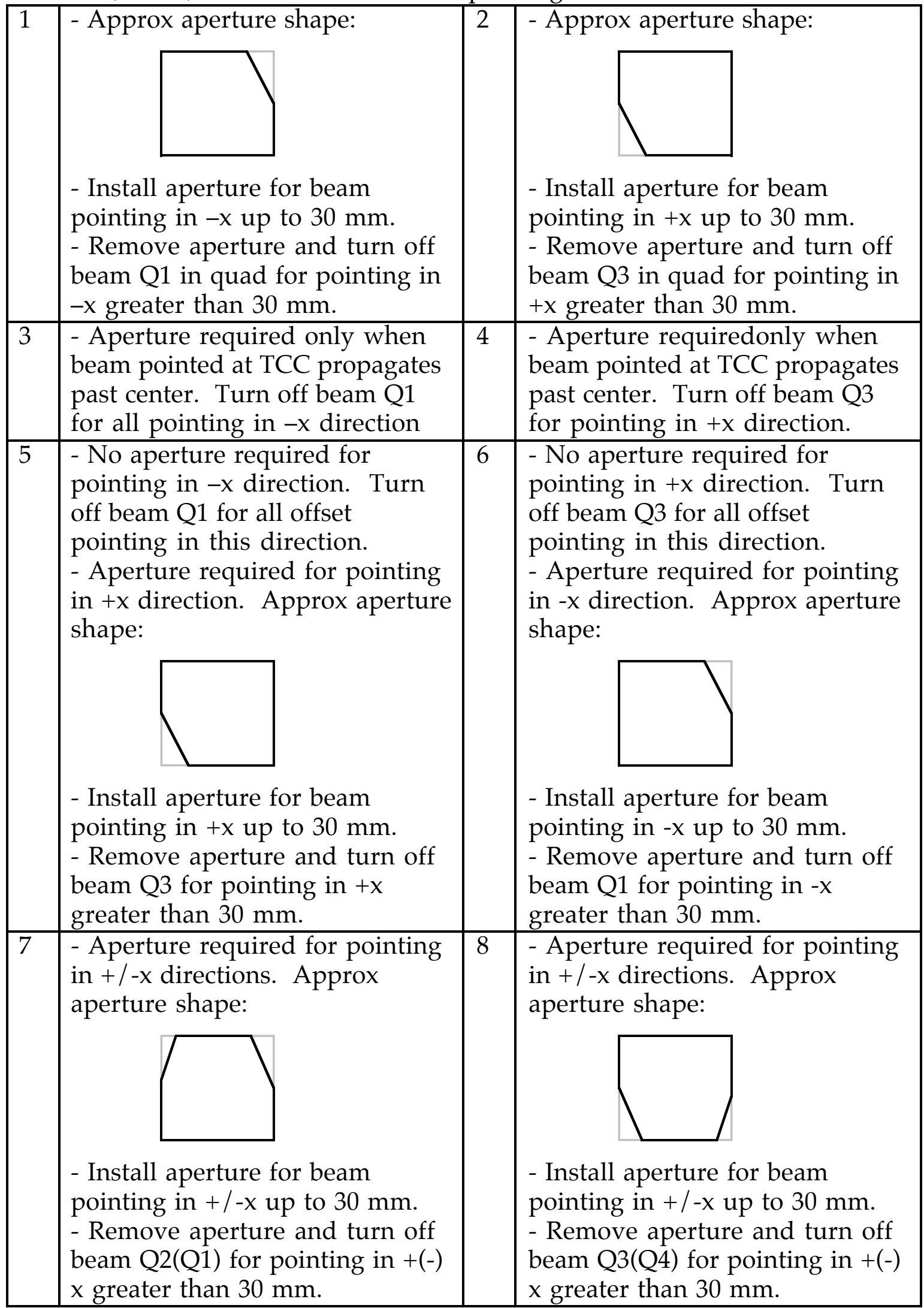


Figure 1: Projection of the top half of the NIF target chamber showing the top beam quads entering through the FOA apertures in the first wall and the $1 \mathrm{w}$ unconverted light footprint from the bottom quads incident on the first wall.



Footprint of lower quad on wall

Quad of 4 beams entering chamber 
Figure 2: Close-up view of the proximity of one quad of beams with a nearopposite FOA.

a) proximity of $1 \mathrm{w}$ footprint with near-opposite port

b) proximity of $3 w$ footprint with near-opposite port

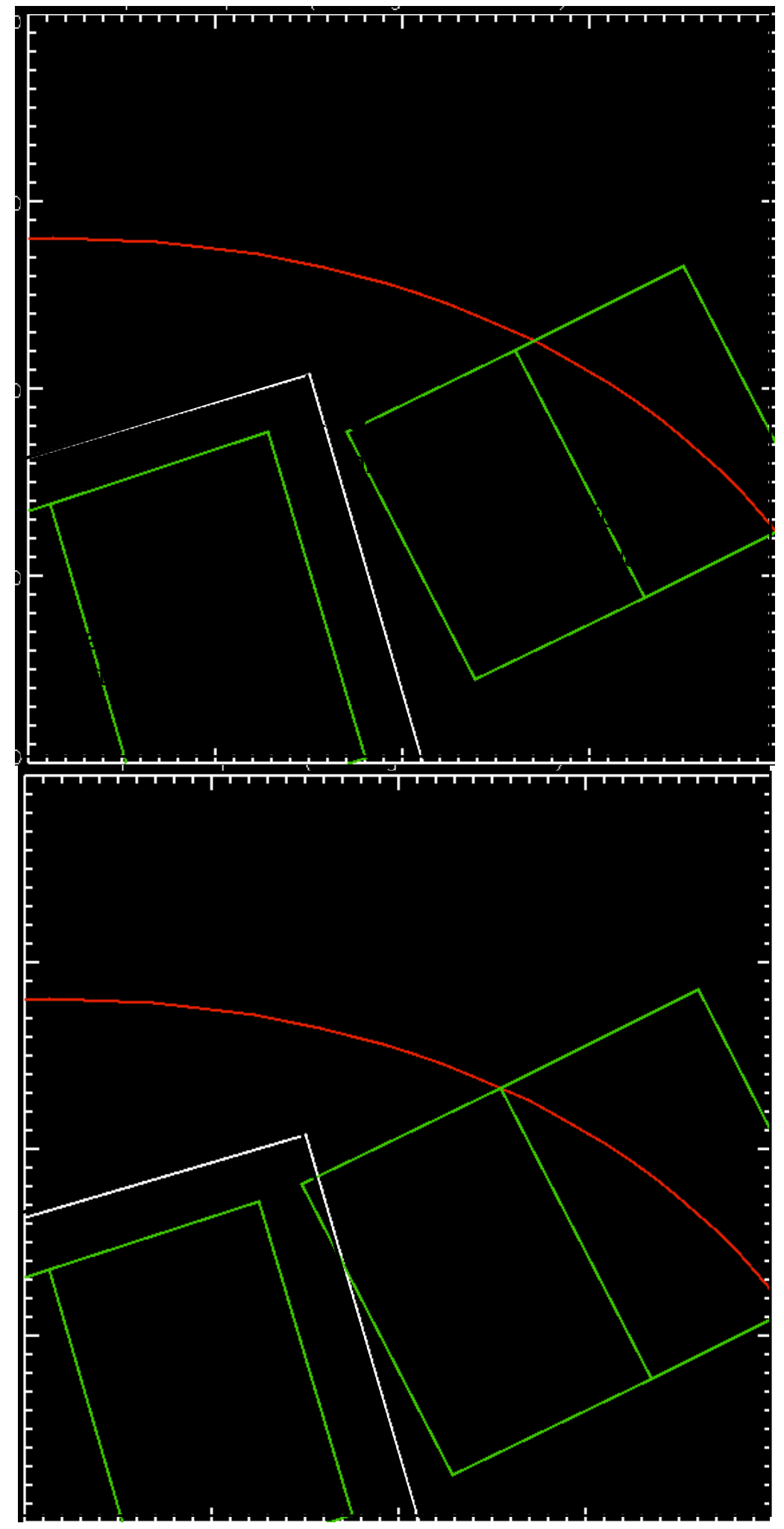


Figure 3: Diagram showing the coordinate system assumed for specifying beam pointing direction and beamlet identification (from NIF Drawing AAA96-104900).

a) Coordinates for a quad of beams

Top of chamber
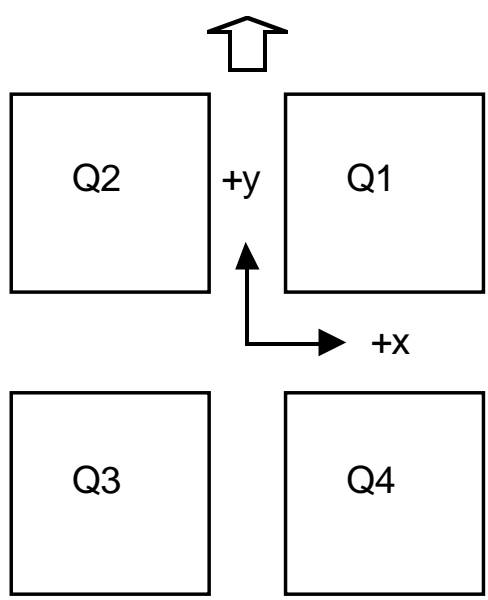

View looking towards chamber b) Beam pointing coordinates

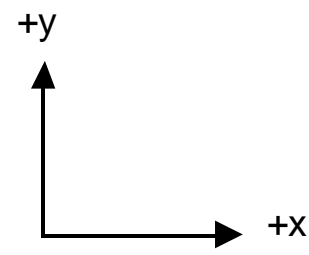

Alignment directions as viewed along beamline toward chamber center 

